\title{
APLIKASI INFORMASI DOKTER SPESIALIS DI BANDAR LAMPUNG BERBASIS ANDROID DENGAN MENGGUNAKAN TEKNOLOGI LOCATION BASE SERVICE
}

\author{
${ }^{1}$ Nurmayanti, ${ }^{2}$ Aristoteles, ${ }^{3}$ Astria Hijriani \\ ${ }^{1}$ Jurusan Ilmu Komputer FMIPA Unila
}

\begin{abstract}
The research conducted to make information system of medical specialist based on Android in Bandar Lampung is using location based service technology. Data used in this research are data of medical specialist that are information of name list of medical specialist in Bandar Lampung, medical specialist, location of practice, schedule of practice, location contact of practice, latitude and longitude of practice location. Funcional testing using equivalence partitioning method creates an application that it can show page of splash screen, page of main menu, page of location menu, page of specialist menu, page of medical list menu, map, page of about, page of help and it can give information of medical specialist list, medical specialist, location of practice and schedule of practice in Bandar Lampung. This application is successfully run in android jelly bean, kitkat, lollipop, and marshmallow version. Non-funcional testing using likert scale is given to 40respondens of society that obtain score of average total 4,05 for user friendly variable and 4,1 for score of interactive variable, so both of them include in 'good' category. Therefore, 10 respondens of medical student having 4,37 for user friendly variable successfully get 'the best' category and 4,2 for interactive variable get 'good' category.
\end{abstract}

Keywords:Android, Bandar Lampung, Location Based Service, SkalaLikert, Specialist Doctor

\section{Pendahuluan}

Dokter spesialis adalah dokter yang mengetahui semua penyakit pada sebagian (satu organ atau satu sistem) tubuh manusia [1], atau dokter yang dikhususkan dalam bidang ilmu kedokteran untuk penyakit tertentu. Di kota Bandar Lampung informasi tentang dokter spesialis masih minim, sehingga masyarakat yang membutuhkan pelayanan dari dokter spesialis kesulitan untuk mencari informasi praktik dokter spesialis. Hal ini disebabkan karena dokter spesialis yang ada tidak hanya praktik dalam satu lokasi. Tidak hanya masyarakat di Bandar Lampung yang kesulitan untuk mencari informasi, masyarakat luar Bandar Lampung yang sedang berkunjung di Bandar Lampung juga kesulitan untuk menemukan dokter spesialis di Bandar Lampung.

Akan tetapi saat ini belum terdapat aplikasi yang dapat mempermudah pengguna untuk menemukan dan mendapatkan informasi dokter spesialis di Bandar Lampung. Oleh karena itu dibutuhkan suatu aplikasi yang dapat memudahkan pengguna untuk menemukan dan mendapatkan informasi dokter spesialis di Bandar Lampung, aplikasi ini diharapkan dapat memudahkan pengguna untuk mendapatkan informasi dan mencari lokasi praktik dokter spesialis di Bandar Lampung. Ariyansah dkk., melakukan penelitian terkait lokasi praktik dokter dengan membangun aplikasi sistem informasi geografis praktek dokter di kota Palembang berbasis android. Android merupakan sistem operasi mobile yang tumbuh di tengah sistem operasi lainnya [2]. Hasil dari penelitian yaitu berupa aplikasi dapat memberikan informasi kepada masyarakat mengenai data praktek dokter di kota Palembang berbasis android. Aplikasi dilengkapi dengan peta navigasi dan detail data dokter praktek [3].

Untuk mengetahui jarak antara pengguna dan lokasi tujuan yaitu dengan memanfaatkan teknologi location based service. Location Based Service (LBS) adalah layanan bisnis dan pelanggan yang memberikan kepada pengguna sekumpulan layanan mulai dari penentuan posisi geografis dari pelanggan [4]. Penelitian

\footnotetext{
${ }^{2}$ Gunakan references - Insert Footnote untuk catatan kaki
} 
sebelumnya terkait penggunaan location based servicedilakuan oleh Razaq dan Jananto, yaitu membangun aplikasi sistem informasi publik layanan kesehatan menggunakan teknologi location based service di kota Semarang. Hasil dari penelitian tersebut yaitu berupa aplikasi yang dapat memberikan kemudahan, kecepatan, dan ketepatan dalam mengetahui posisi geografis lokasi layanan kesehatan terdekat di sekitar pengguna [5]. Berdasarkan permasalahan dan juga dengan adanya penelitian sebelumnya, maka akan dibangun aplikasi informasi dokter spesialis di Bandar Lampung berbasis android dengan menggunakan teknologi location based service, yang dapat digunakan untuk memberikan informasi berupa lokasi praktik, spesialisasi dokter, daftar nama dokter, jadwal praktik dokter, rute lokasi praktik dokter, dan kontak yang dapat dihubungi. Dengan harapan agar dapat membantu masyarakat untuk mendapatkan informasi dokter spesialis di Bandar Lampung.

\section{Metodologi Penelitian}

Metodologi pengembangan sistem yang digunakan yaitu Rational Unifed Process (RUP) dan desain menggunakan Unifed Modeling Language.Rational Unifed Process (RUP) merupakan suatu metode rekayasa perangkat lunak yang dikembangkan dengan mengumpulkan berbagai best practices yang terdapat dalam industri pengembangan perangkat lunak [6], sedangkan Unified Modeling Language (UML) adalah keluarga notasi grafis yang didukung oleh meta-model tunggal, yang membantu pe ndeskripsian dan desain sistem perangkat lunak, khususnya sistem yang dibangun menggunakan pemrograman berorientasi objek [7].

\subsection{Alir Penelitian}

Penelitian dilakukan berdasarkan diagram alir metodologi penelitian terdapat pada Gambar 1.Penjelasan diagram alir metodologi penelitian pada Gambar 1 adalah sebagai berikut.

\subsubsection{Langkah I}

1. Pada langkah pertama tahap pertama yang dilakukan yaitu mengidentifikasi masalah. Identifikasi masalah bertujuan untuk menemukan masalah yang akan dikaji dalam penelitian. Masalah yang ditemukan akan menentukan seberapa besar kualitas dari penelitian yang dilakukan. Identifikasi masalah dapat menentukan apakah penelitian perlu atau tidak untuk dilakukan.

2. Tahap kedua yaitu perumusan masalah, perumusan masalah yaitu pertanyaan dari penelitian yang akan dibangun dalam bentuk kalimat tanya.

3. Tahap ketiga yaitu menentukan tujuan, manfaat, dan batasan. Target pencapaian pada tahap ini yaitu diketahuinya tujuan serta manfaat yang akan diperoleh dalam pembangunan aplikasi informasi dokter spesialis di Bandar Lampung. Sedangkan batasan digunakan untuk membatasi ruang lingkup penelitian.

4. Tahap keempat yaitu survei pendahuluan, survei pendahuluan dilakukan untuk mengetahui halhal penting yang berhubungan dengan penelitian yang akan dikaji.

5. Tahap kelima yaitu studi literatur, studi literatur dilakukan untuk mendapatkan teori-teori dan hasil penelitian sebagai gambaran dan dijadikan sebagai landasan teori. 


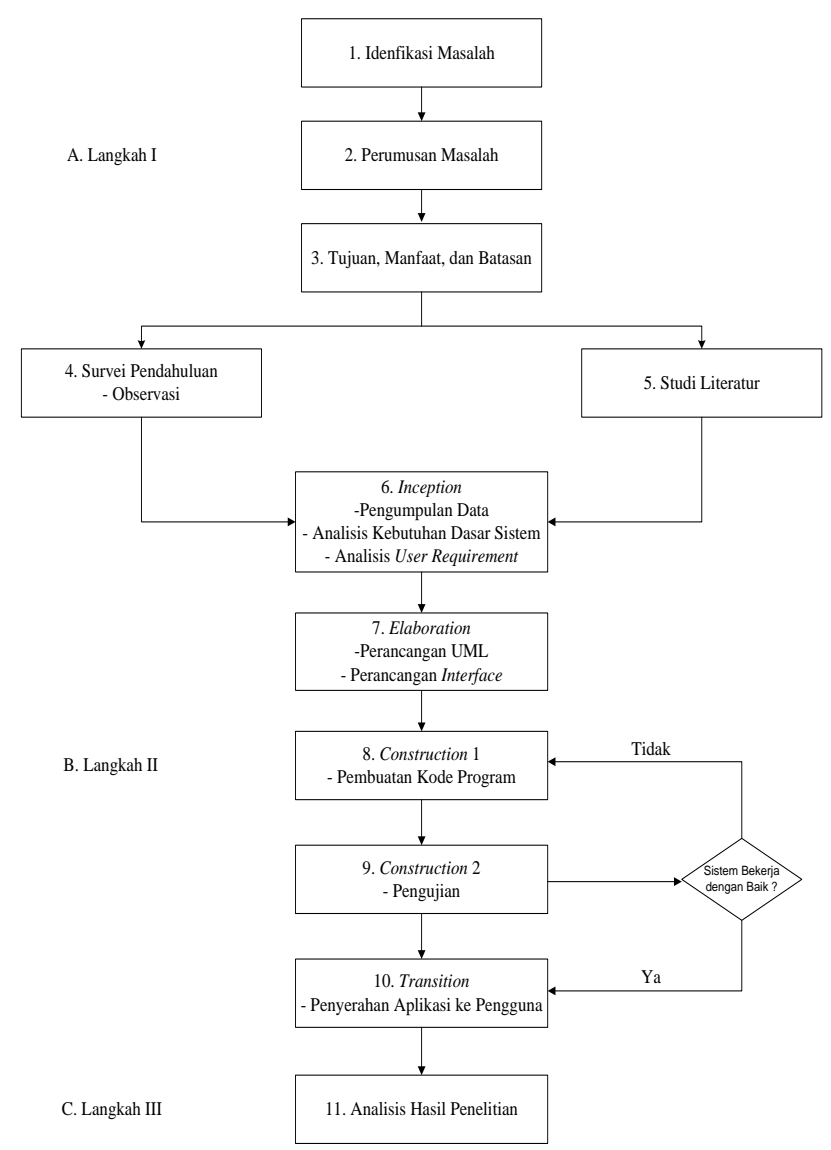

Gambar 1 Diagram alir penelitian

\subsubsection{Langkah II}

6. Langkah kedua merupakan pengembangan sistem menggunakan metode Unified Process. Tahap keenam yang dilakukan dalam pengembangan sistem yaitu inception. Pada tahap ini dilakukan pengumpulan data berupa titik lokasi dan informasi praktik dokter. Informasi yang dikumpulkan yaitu nama dokter, tempat praktik, waktu praktik. Pada tahap ini juga dilakukan analisis kebutuhan dasar sistem dan analisis kebutuhan pengguna.

7. Tahap ketujuh yaitu elaboration, pada tahap ini dilakukan perancangan dengan menggunakan Unified Modelling Language (UML) dan dilakukan perancangan interface atau perancangan antarmuka yang bertujuan untuk merancang tata letak sistem sesuai dengan analisis kebutuhan.

8. Tahap kedelapan yaitu construction 1, pada tahap ini dilakukan pembuatan kode program.

9. Tahap kesembilan yaitu construction 2, pada tahap ini akan dilakukan pengujian program. Pengujian dilakukan menggunakan pengujian blackbox dengan metode equivalence partitioning. Jika program yang dibuat tidak sesuai dengan kebutuhan maka akan kembali ke tahap construction 1.

10. Tahap kesepuluh yaitu transition, pada tahap ini dilakukan penyerahan aplikasi ke pengguna.

\subsubsection{Langkah III}

11. Tahap kesebelas yaitu analisis hasil penelitian, pada tahap ini dilakukan untuk mengetahui hasil yang diperoleh apakah sudah memenuhi permasalahan yang dideskripsikan di awal. 


\subsection{Perancangan Unifed Modeling Language (UML)}

Perancangan sistem dilakuakan dengan memodelkan permasalahan dalam bentuk diagram-diagram UML sebagai berikut.

\subsubsection{Use case diagram}

Use case diagram digunakan untuk menggambarkan fungsi dari sistem terhadap pengguna. Pada aplikasi pengguna dapat melakukan beberapa interaksi yaitu pengguna dapat mengakses mengakses menu lokasi, mengakses menu sepesialisasi untuk melihat infromasi berdasarkan spesialisasi dan melihat lokasi praktik dalam bentuk map, mengakses menu daftar dokter untuk melihat informasi dokter dan melihat lokasi praktik dalam bentuk map, mengakses menu map, mengakses menu bantuan, dan mengakses menu tentang. Berikut adalah gambaran use case diagram yang ditunjukan pada Gambar 2.

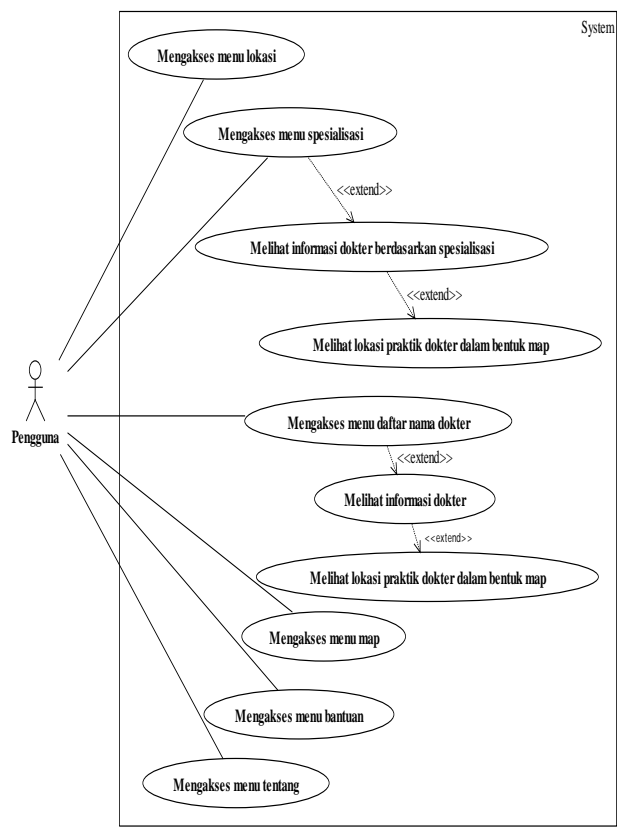

Gambar 2Use casediagram

\subsubsection{Class diagram}

Class diagram mendeskripsikan jenis-jenis objek dalam sistem dan berbagai macam hubungan statis yang terjadi. Pada aplikasi informasi dokter spesialis terdapat 3 (tiga) kelas yang dibangun, yaitu data dokter, jadwal, dan tempat. Class diagram aplikasi informasi dokter spesialis disajikan pada Gambar3.

\begin{tabular}{|c|c|c|}
\hline \multirow[b]{2}{*}{ Data_Dokter } & \multirow[b]{2}{*}{ Jadwal } & \multirow{2}{*}{\begin{tabular}{|r|} 
Tempat \\
+id tempat
\end{tabular}} \\
\hline & & \\
\hline $\begin{array}{l}\text { +id_dokter } \\
\text { +nama } \\
\text { +spesialisasi }\end{array}$ & \multirow{2}{*}{$\begin{array}{l}\text { +id_jadwal } \\
\text { +id_dokter } \\
\text { +id_tempat } \\
\text { +jadwal_praktik }\end{array}$} & $\begin{array}{l}\text { +nama_tempat } \\
\text { +telp_tempat } \\
\text { +latitude }\end{array}$ \\
\hline \multirow{2}{*}{$\begin{array}{l}\text { + getNama() } \\
\text { + getSpesialisasi() }\end{array}$} & & +longitude \\
\hline & +get] adwal_Praktik() & + getNamn_Tempat() \\
\hline
\end{tabular}


Gambar 3 Class diagram

\section{Hasil dan Pembahasan}

Aplikasi Informasi Dokter Spesialis di Bandar Lampung adalah aplikasi yang dibangun untuk mendapatkan informasi berupa lokasi praktik, spesialisasi dokter, daftar nama dokter, jadwal praktik dokter, rute lokasi praktik dokter, dan kontak tempat praktik dokter di Bandar Lampung dengan menggunakan teknologi Location Based Service.Aplikasidibangunmenggunakan android studio dan SQLite Managersebagai database.

Berikut adalah layout menu-menu yang ada pada aplikasi informasi dokter spesialis di Bandar Lampung.

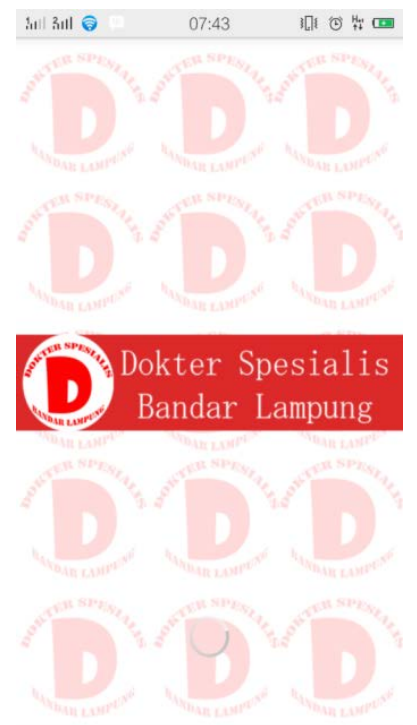

Gambar 4

Tampilanhalamansplash screen

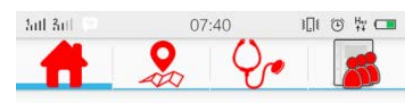

(i) ?

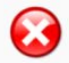

Gambar5 Tampilanhalaman menu utama

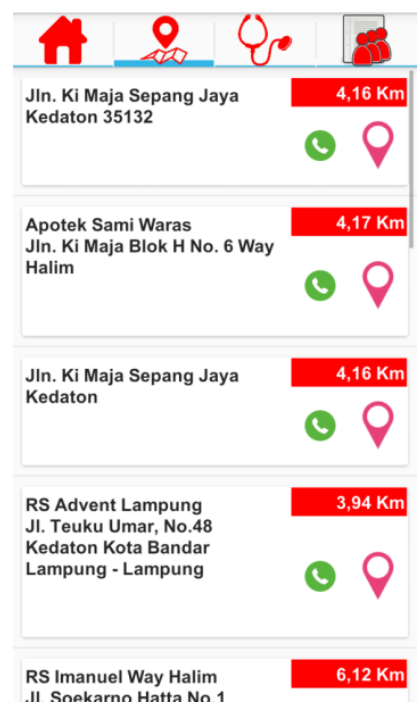

Gambar6 Tampilanhalaman menu lokasi

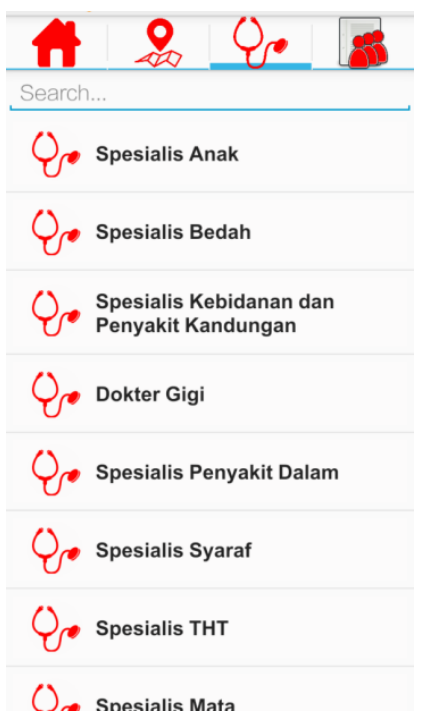

Gambar7 Tampilanhalaman menu spesialis

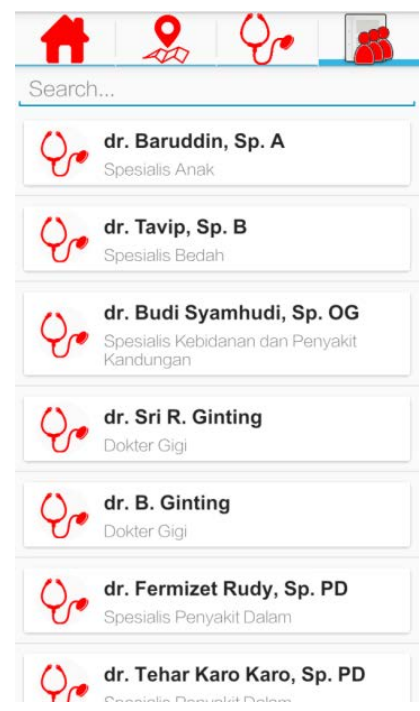

Gambar8 Tampilanhalaman menu daftarnamadokter

$$
\text { U dr. Baruddin, Sp. A }
$$

Jin. Ki Maja Sepang Jaya Kedaton 35132

Senin - Jumat

Pagi: $07.30-09.00$

Sore : $16.30-20.00$

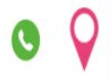

RS Advent Lampung

JI. Teuku Umar, No.48

Kedaton Kota Bandar

Lampung - Lampung

Setiap Hari Kerja

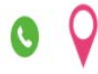

Gambar9 Tampilanhalaman menu informasidokter 


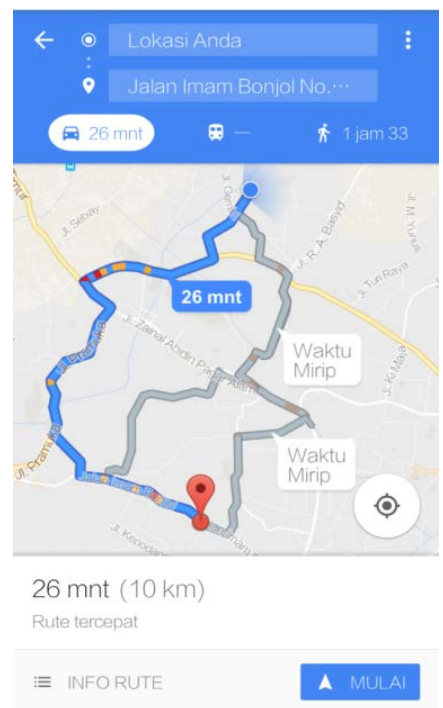

Gambar10 Tampilanhalaman menu rutelokasi

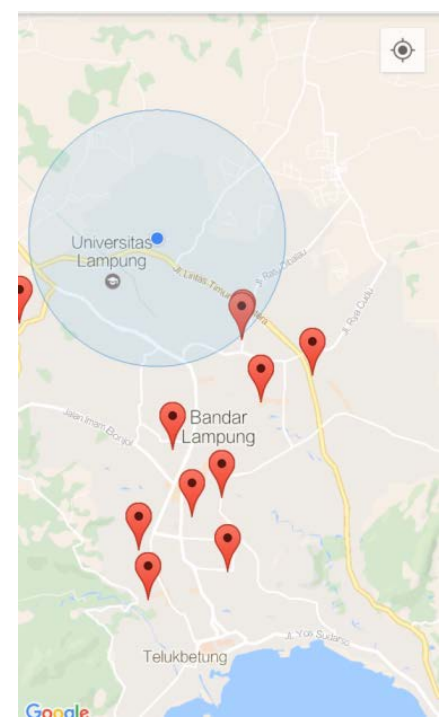

Gambar11 Tampilanhalaman map

\subsection{Pengujian Sistem}

Pengujian dilakukan secara fungsional dan non fungsional. Secara fungsional pengujian menggunakan black box testing, teknik pengujian black box berfokus pada domain informasi dari perangkat lunak, yaitu melakukan kasus uji dengan mempartisi domain input dan output program[8], dan dengan menggunakan metode equivalence partitioning. Equivalence Partitioning (EP) merupakan metode black box testing yang membagi domain masukan dari program kedalam kelas-kelas sehingga test case dapat diperoleh[9].

Tabel 1 Pengujian secara fungsional

\begin{tabular}{|c|c|c|c|c|c|}
\hline No & Kelas Uji & Daftar Pengujian & Skenario Uji & $\begin{array}{c}\text { Hasil yang } \\
\text { Diharapkan }\end{array}$ & $\begin{array}{l}\text { Hasil yang } \\
\text { Diperoleh }\end{array}$ \\
\hline 1 & $\begin{array}{c}\text { Versi } \\
\text { android }\end{array}$ & $\begin{array}{c}\text { Pengujian } \\
\text { kompabilitas versi } \\
\text { Operating System } \\
\text { (OS) android }\end{array}$ & $\begin{array}{l}\text { Pengujian pada } \\
\text { android versi } 4.1 \text {, } \\
\text { 4.4, 5.0, } 6.0 \text {. }\end{array}$ & $\begin{array}{c}\text { Kompatibel } \\
\text { dengan android } \\
\text { versi } 4.1,4.4,5.0 \text {, } \\
6.0 .\end{array}$ & $\begin{array}{c}\text { Berhasil } \\
\text { Kompatibel } \\
\text { dengan android } \\
\text { versi } 4.1,4.4 \text {, } \\
5.0,6.0 . \\
\end{array}$ \\
\hline 2 & $\begin{array}{l}\text { Resolusi } \\
\text { layar dan } \\
\text { densitas } \\
\text { layar }\end{array}$ & $\begin{array}{c}\text { Resolusi layar dan } \\
\text { densitas layar }\end{array}$ & $\begin{array}{l}\text { Pengujian pada } \\
\text { android dengan } \\
\text { resolusi } 4 \text { inch, } \\
\text { 4,5 inch, 4,8 inch, } \\
5 \text { inch, 5,5 inch }\end{array}$ & $\begin{array}{l}\text { Tampilan sesuai } \\
\text { dan proporsional } \\
\text { dengan resolusi } 4 \\
\text { inch, } 4,5 \text { inch, } 4,8 \\
\text { inch, } 5 \text { inch, 5,5 } \\
\text { inch }\end{array}$ & $\begin{array}{c}\text { Berhasil } \\
\text { Tampilan } \\
\text { proporsional } \\
\text { dengan resolusi } \\
4 \text { inch, } 4,5 \text { inch, } \\
\text { 4,8 inch, } 5 \text { inch, } \\
\text { 5,5 inch } \\
\end{array}$ \\
\hline 3 & $\begin{array}{c}\text { User } \\
\text { Interface }\end{array}$ & $\begin{array}{c}\text { Pengujian menu } \\
\text { utama }\end{array}$ & $\begin{array}{l}\text { Pengujian menu } \\
\text { lokasi, menu } \\
\text { spesialisasi, menu } \\
\text { daftar dokter, dan } \\
\text { menu tampilan } \\
\text { map }\end{array}$ & $\begin{array}{l}\text { Menampilkan } \\
\text { halaman dengan } \\
\text { menu lokasi, } \\
\text { menu spesialisasi, } \\
\text { menu daftar } \\
\text { dokter, dan menu } \\
\text { tampilan map }\end{array}$ & $\begin{array}{c}\text { Berhasil } \\
\text { Menampilkan } \\
\text { halaman menu } \\
\text { lokasi, menu } \\
\text { spesialisasi, } \\
\text { menu daftar } \\
\text { dokter, dan }\end{array}$ \\
\hline
\end{tabular}


Pengujian non fungsioanl menggunakan skala likert yang melibatkan 50 responden. Menurut Likert, sikap dapat diukur dengan metode rating yang dijumlahkan (Method of Summated Ratings). Metode ini merupakan metode penskalaan pernyataan sikap yang menggunakan distribusi respon sebagai dasar penentuan nilai skalanya [10].Pengujian dibagi menjadi dua yaitu pengujian berdasarkan user friendly dan pengujian berdasarkan variable interaktif.

Sebelum dilakukan perhitungan dengan skala likert, dilakukan perhitungan interval. Perhitungan dilakukan dengan menggunakan persamaan sebagai berikut.

$I=\frac{\mathrm{NT}-\mathrm{NR}}{\mathrm{K}}(1)$

$$
I=\frac{5-1}{5}=0,8
$$

Setelah besarnya interval diketahui, kemudian dibuat rentang skalase hingga diketahui dimana letak ratarata penilaian responden terhadap setiap poin variabel. Rentang skala disajikan pada Tabel2.

Tabel2 Interval dan kategori penilaian

\begin{tabular}{cc}
\hline Interval & Kategori \\
\hline $4,23-5,04$ & Sangatbaik (5) \\
\hline $3,42-4,23$ & Baik (4) \\
\hline $2,62-3,42$ & Cukupbaik (3) \\
\hline $1,81-2,61$ & Kurangbaik (2) \\
\hline $1,00-1,80$ & Tidakbaik (1)
\end{tabular}

Hasil penilaian variable user friendly untuk 40 (empat puluh) responden yang melibatkan mahasiswa/mahasiswi dan masyarakat umum, dan 10 responden mahasiswa/mahasiswi kedokteran disajikan pada Grafik 1.

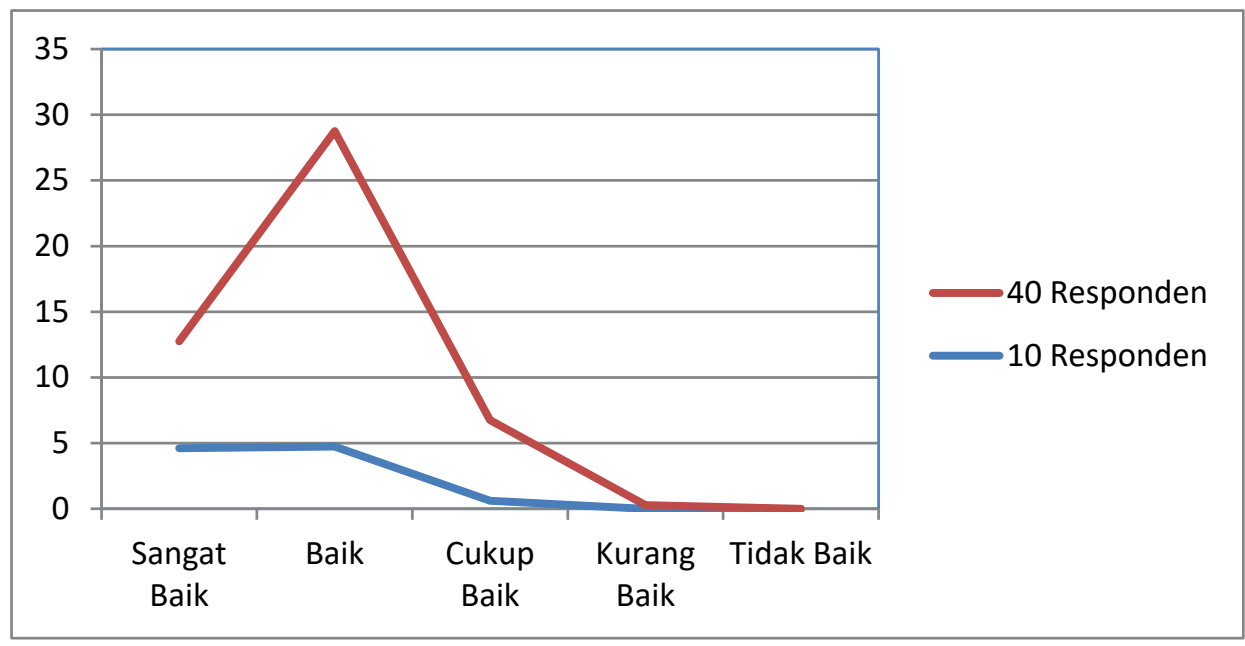

Grafik 1 Hasil penilaian pengujian secara user friendly

Total rata-rata yang diperoleh pada variable user friendly untuk 40 responden adalah 4,06 masuk kedalam kategori “baik”, dan 4,37 untuk 10 responden masuk kedalam kategori “sangatbaik”.

Hasil penilaian variable interaktif untuk 40 dan 10 responden disajikan pada Grafik 2. 


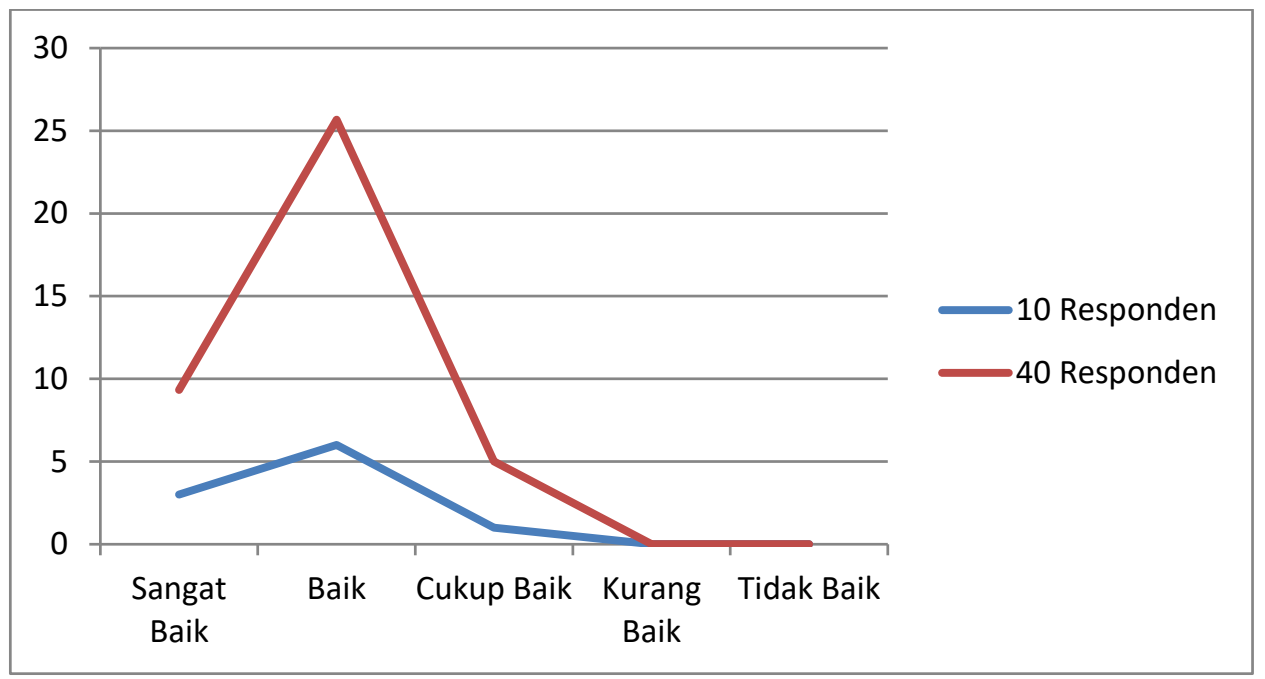

Total rata-rata yang diperoleh pada variable interaktif untuk 40 responden adalah 4,1 masuk kedalam kategori “baik”, dan 4,2 untuk 10 responden masuk kedalam kategori “baik”..

\section{Kesimpulan}

Dari hasil penelitian yang dilakukan, penulis dapat mengambil simpulan sebagai berikut.

1. Aplikasi Informasi Cari Dokter Spesialis berhasil dibangun dan menghasilkan informasi berupa daftar dokter spesialis, spesialisasi dokter, lokasi praktik dan waktu praktik dokter spesialis di Bandar Lampung.

2. Dari pegujian versi android jelly bean, kitkat, lollipop, dan marshmallow aplikasi berhasil dijalankan dan kompatibel, dan tampilan sesuai pada resolusi layar 4 inch, 4,5 inch, 4,8 inch, 5 inch, dan 5,5 inch.

3. Dari pengujian user interface yang dilakukan, berdasarkan test case yang diberikan aplikasi dapat menampilkan halaman splash screen, halaman menu utama, halaman menu lokasi, halaman menu spesialisasi, halaman menu daftar dokter, tampilan map, halaman tentang, dan halaman bantuan.

4. Pengujian diberikan kepada 40 responden yang melibatkan mahasiswa/mahasiswi dan masyarakat umum dan 10 responden dari mahasiswa kedokteran. Hasil penilaian secara user friendly untuk 40 responden memiliki total rata-rata 4,05 masuk ke dalam kategori 'baik', dan 10 responden memiliki total rata-rata 4,37 dan masuk ke dalam kategori 'sangat baik'. Sedangkan penilaian variabel interaktif untuk 40 responden memiliki total rata-rata 4,1 masuk ke dalam kategori 'baik, dan 10 responden memiliki total rata-rata 4,2 masuk ke dalam kategori 'baik’.

\section{Saran}

1. Diharapkan aplikasi dapat melakukan pencarian rute lokasi praktik dokter dengan baik dalam kondisi koneksi internet yang kurang stabil.

2. Diharapkan aplikasi dapat menampilkan foto lokasi praktik maupun foto dokter spesialis di Bandar Lampung.

3. Diharapkan aplikasi dapat terus memperbaharui informasi dokter spesialis berupa daftar dokter, lokasi praktik dan jadwal praktik.

4. Diharapkan aplikasi dapat melalukan update data secara otomatis agar aplikasi dapat terus berjalan dan digunakan.

5. Diharapkan aplikasi dapat dikembangkan di kemudian hari agar dapat secara otomatis menampilkan jadwal libur atau cuti dokter spesialis.

6. Aplikasi ini nantinya dapat dikembangkan sehingga kompatibel pada platform selain android, seperti iOS, BlackBerry OS ataupun Windows Phone.

\section{Referensi}


[1] Hanafiah, M. J. dan Amir A.,EtikaKedokteran\&HukumKesehatan,Jakarta :PenerbitBukuKedokteran EGC, (2009).

[2] Safaat, Nazruddin,PemrogramanAplikasi Mobile Smartphone dan Tablet PC Berbasis Android,Bandung :Informatika, (2012).

[3] Ariyansah, dkk.,SistemInformasiGeografisPraktekDokter di Kota Palembang Berbasis Android. Palembang :UniversitasBinaDarma, (2012).

[4] Hartanto, Antonius A.,MengenalAspekTeknisdanBisnis Location Based Service,Jakarta :Elex Media Komputindo, (2003).

[5] Rajaq, J.A. danJananto, A., SistemInformasiPublikLayananKesehatanMenggunakanMetode Location Based Service di Kota Semarang, JurnalTeknologiInformasiDinamika Vol. 19, No. 1, : 5967. ISSN : 0854-9524, (2014).

[6] Nugroho, Adi, RekayasaPerangkatLunakBerorientasiObjekdenganMetode USDP,Jakarta :Andi, (2010).

[7] Fowler, Martin,UML Distilled Edisi 3 PanduanSingkatBahasaPermodelanObjekStandar, Yogyakarta :Andi Publishing, (2004).

[8] Pressman, R.S., Software Engineering : A Practitioner's Approach, 7th Edition, New York : McGraw-Hill, (2010).

[9] Pressman, R.S.,RekayasaPerangkatLunak :pendekatanpraktisi (Buku1). Beizer, B. (1995). BlackBox Testing, Wiley, Yogyakarta :Andi Publishing, (2007) 